\title{
Multistability and Derrida's Différance: Investigating the Relations Between Postphenomenology and Stiegler's General Organology
}

\author{
Marco Pavanini ${ }^{1}$
}

Received: 20 July 2021 / Accepted: 12 January 2022 / Published online: 24 January 2022

(C) The Author(s) 2022

\begin{abstract}
In this paper, in the first place, I aim to enquire into Bernard Stiegler's critical appropriation of his mentor Jacques Derrida's notion of différance, emphasizing how Stiegler's philosophy of technology stems from an original interpretation of the main tenets of deconstruction. From this perspective, I will investigate Stiegler's definition of technology as tertiary retention, i.e., exosomatized, artificial memory interrelating with biological memory, testing its hermeneutic strengths as well as possible weaknesses. In the second place, I aim to contrast Stiegler's understanding of technology with the concept of multistability brought forward by postphenomenological philosophies of technology such as those elaborated by Don Ihde and Peter-Paul Verbeek. This investigation will enable me to submit that Stiegler's approach represents a peculiar and innovative way to conceive of technology. On the one hand, indeed, it does not seem to fall prey to the criticisms raised by postphenomenology against traditional philosophies of technology such as Martin Heidegger's or Jacques Ellul's, deemed to be overly deterministic, abstract and pessimistic in their understanding of technology. On the other, it retains important methodological precautions from deconstruction, thereby pointing at some possible blind spots of postphenomenology, especially concerning the vexed question of the empirical-transcendental divide, which Stiegler aims to develop beyond both Derrida's and postphenomenology's stances.
\end{abstract}

Keywords Bernard Stiegler · Jacques Derrida · Postphenomenology · Différance · Multistability $\cdot$ Technology

This article is part of the Topical Collection on Philosophy of Technology and the French Thought.

Marco Pavanini

marco.pavanini1@gmail.com

1 School of Modern Languages and Cultures, Durham University, Elvet Riverside, New Elvet, Durham DH1 3JT, UK 


\section{Introduction}

Philosophy, since its Hellenic origins, has always somehow vaguely dealt with tékhne, initially conceived of as a way of making and doing. While such an implicit engagement with technology has been developed in multifarious ways within different cultures-as cogently shown by Yuk Hui in The Question Concerning Technology in China (2016: 3-57) — however, a philosophy of technology strictly speaking seems only to emerge starting from the nineteenth century in the western world. Indeed, the increasing pervasiveness of technological development brought forward by the second industrial revolution fostered the interest in "technology" as the study, classification and formalization of the individual technologies and their related modes of construction and employment. This condition enabled, in turn, the establishment of "philosophy of technology" as a critical reflection on the relations between humans and their artefacts, as exemplified by Ernst Kapp's (2018) seminal book Elements of a Philosophy of Technology, published in 1877. In the twentieth century, technology became an increasingly significant concern for philosophy, concomitantly with the massive advances in technological innovation covering nearly every aspect of existence-from medicine to warfare, from communication to agriculture, from education to entertainment, and so on. Gradually, philosophy of technology constituted itself as a relatively independent subdiscipline, eminently exemplified by postphenomenology, the approach initiated by Don Ihde's groundbreaking work Technics and Praxis, published in 1979.

Nowadays, the "question concerning technology"- sometimes also referred to as "technics", a rather obsolete English word translating the French technique and the German Technik-seems to represent a major field of enquiry within philosophical speculation, with many theoretical lineages investigating the issue from different perspectives-from posthumanism to philosophical anthropology and cultural studies, just to name a few. Perhaps surprisingly, however, "French thought", i.e., the set of philosophical approaches elaborated in France starting from the second half of the twentieth century, despite its pivotal contribution to philosophy in general, never properly developed a philosophy of technology — as lamented by Daniel Parrochia (2009), for instance. In their review, Sacha Loeve, Xavier Guchet and Bernadette Bensaude Vincent (2018) submit a more nuanced interpretation: a French philosophy of technology strictly speaking would have not emerged so far mainly because contemporary French philosophers have always been thematically dealing with technology, albeit trying to understand it per se, rather than mostly enquiring into the individual, concrete technologies. Thus, a widespread tendency to more or less explicitly equate the question concerning technology with a most general and all-encompassing metaphysical question would have prevented French scholars from focusing on the actual specificities of the different technologies composing our lifeworld, thereby risking losing methodological consistency and thematic focus when compared with more systematic and scientifically minded approaches to the study of technology.

From this viewpoint, the relation between French thought and philosophy of technology seems to remain underdeveloped at the moment. In what follows, I aim to 
provide some elements for a dialogue bringing these two approaches closer together by drawing our attention to Bernard Stiegler's work. On the one hand, Stiegler can be considered a philosopher of technology proper, insofar as he places the question of technology as well as the analysis of individual technologies at the core of his philosophy. Indeed, he states that technology would represent nothing less than philosophy's unthought, i.e., what the latter always neglected, thereby failing to properly address what he believes to be the mainspring of human evolution and development (Stiegler, 1998: 1-3). On the other, Stiegler rightly belongs to the tradition of French thought as well, since his work originates starting from a critical appropriation of the intellectual legacy of his mentor Jacques Derrida, the founder of deconstruction and one of the most influential twentieth-century French philosophers. I believe that these two circumstances are strictly interconnected, insofar as Stiegler's thinking of technology is expounded as a critical correction and extension of Derrida's thinking of différance. As I aim to show, Stiegler's conceptualization of technology's specificity aims to overcome what he believes to be a blind spot of deconstruction, which is deemed to neglect technology quite as much as philosophy in general has done so far.

Thus, I submit that a dialogue between Stiegler's stance and mainstream philosophy of technology becomes possible precisely if we focus our attention on Stiegler's original appropriation of French thought. Although contemporary philosophy of technology represents a multifaceted field of study, ranging from Andrew Feenberg's (2002) critical constructivism to science and technology studies (e.g., Jasanoff, 2019; Latour, 2005), for instance, in what follows I will limit myself to a discussion of the postphenomenological approach elaborated by Ihde (1979, 1990, 2010) and Peter-Paul Verbeek $(2005,2011)$ especially. I will argue that Stiegler's and postphenomenology's approaches share a functional conception of technology, i.e., they both think of technology as something that is not aprioristically determinable in its essence, but rather only emerges within its relationship with humans and is conceivable only starting from this relationship. However, I will also maintain that Stiegler's understanding of human-technology relations, rooted in evolutionary anthropology, is more radical than that purported by postphenomenologists, insofar as for him this condition holds also reciprocally, i.e., humans may exist only through their relationship with technology and are thinkable only starting from this relationship. In my view, this perspective enables Stiegler, contrary to Ihde and Verbeek, to enquire into how technology not only constitutes our lifeform, but may also destitute it, dismantling our humanity.

\section{Technology and Différance}

The stake here is the interpretation of Derrida's notion of différance. As discussed in his famous essay with the same name (Derrida, 1982), this rather enigmatic term should not be understood as a concept or a word proper; it rather denotes something that does not exist, is not a being-present, has no essence. Différance, Derrida argues, is pure movement, already plural and non-simple in its origin, for whose understanding our extant conceptual frames are ultimately inadequate. It 
simultaneously refers to both deferral in time and differentiation in space, constituting the originary interplay of time and space, the becoming-space of time (spatialization) and the becoming-time of space (temporalization). Indefinitely producing actual differences, it does not exist before or independently of its individual instantiations. Thus, Derrida's strategic notion aims to deconstruct the oppositions engendered by the originary neglecting of its dynamic by western metaphysical tradition (e.g., form and matter, nature and culture, signified and signifier etc.), ultimately questioning its conception of Being as pure presence.

In Of Grammatology (1997: 60-62), Derrida expands on the notion of différance - also called gramme, trace, supplement or arche-writing — and relates it to the question of the origin, i.e., of its irreducible retreat from the possibility of a "pure" origin, that is origin as a single, describable event which would account for everything that, proceeding from it, it produces. What originates the origin should not be hypostatized as an origin itself; it is rather the paradoxical supplemental logic of constant deferring and differentiating of originary presence. Since the latter is always haunted by absence, devoid of plenitude and self-referential autonomy, the origin only manifests itself by default, i.e., by its disappearance.

Notably, as maintained by Martin Hägglund (2011), différance is a metatheoretical notion whose domain equates with the whole of Being. Thus, while it should not be restricted to what is living alone, it also enables us to account for the history of life in general consistently with neo-Darwinian evolutionary biology, if we understand life as the possibility of an economizing production of differences by continuous deferrals and differentiations of presence. According to Derrida, indeed, "mark, gramma, trace, and différance refer differentially to all living things, all the relations between living and nonliving" (Derrida, 2008: 104). However, while commenting on insights coming from the paleoanthropologist André Leroi-Gourhan (1993), Derrida (1997: 83-86) points out that anthropogenesis, that is the evolutionary emergence of the human lifeform, represents "a stage or an articulation in the history of life —of what I have called differance-as the history of the grammè. [...] It is an emergence that makes the grammè appear as such (that is to say according to a new structure of nonpresence)" (Derrida, 1997: 84). On the one hand, the movement of différance articulates life in general, humans representing just one of the stages of this articulation, as every other organism does. On the other, the human lifeform corresponds with the emergence of the gramme (i.e., différance) "as such".

This is where Stiegler's interpretation sets in. He aims to develop what he calls general organology, i.e., a transdisciplinary study of the human lifeform considering "the body with its physiological organization; artificial organs (technologies, objects, tools, instruments, artworks); and social organizations resulting from the articulation of artefacts and bodies" (Stiegler, 2014: 5). According to Stiegler (1998: 137), humans are technical organisms, i.e., our biology is structurally rearranged by our relations with technologies, so that biological organs, artificial organs and social organizations compose in an originary relation constituting its own termswhat he calls a transductive relation (Stiegler, 2008b: 2), taking up Gilbert Simondon's (2020: 12-16) quite idiosyncratic use of the term. As I will discuss below, Stiegler understands anthropogenesis as the processual interrelation of nervous, genetic and artificial (i.e., technologically inscribed) memory, a process he terms 
epiphylogenesis (Stiegler, 1998: 135). This approach, labelled human constitutive technicity (Havelange et al., 2002), increasingly finds supporting evidence in current scholarship in palaeoanthropology, as exemplified by the work of Richard Wrangham (2009), Kim Sterelny (2012) and Lambros Malafouris (2013), among others.

Throughout anthropogenesis, hominin populations increasingly produce, transmit and utilize technical devices, from simple stone tools to more elaborated cooking, housing or storing techniques. These complexes of socially embedded technologies constitute an artificial environment arising around our ancestors and gradually replacing the former, "natural" environment, supplementing its selection pressures with novel affordances and possibilities of subjectivation. Thus, our psychophysical, behavioural and ecological constitution is the outcome of the feedback effects of our own technologies, which retroact on their producers by selecting for those traits which better fit in with the emerging artificial environment, thereby gaining evolutionary momentum and taking over anthropogenesis-what Gerald Moore (2017), elaborating on Stiegler's insights, calls artificial selection. As pointed out by Sterelny (2012: 33), knapping stones, for instance, may well have debilitating costs in terms of injured fingers and defective tools, but the practice of stone knapping, once it becomes systemic and entrenched within a group's lifestyle, will favour those individuals who result more effective at carrying it out, consequently benefiting from enhanced chances to reproduce and pass on their genes. Indeed, since those traits which prove apt to take advantage of the emerging artificial environment are favoured, their replication will also favour the increasing artificialization of the surrounding living conditions, to the point where humans can relate to the world only through technologies.

Hence, from Stiegler's perspective, humans could not evolve without their relationship with technologies, which have actually selected our genotypes throughout our evolution and constantly mould our phenotypes throughout our development. Moreover, technologies also shape every discourse about the human condition, insofar as the access to information regarding our origins is structured and mediated by particular artefacts. The fossil records of the first Hominins, for instance, can be appreciated and interpreted only thanks to sets of dating, indexing and classification technologies that enable us to detect evidence of our ancestors in what would otherwise probably look like nothing but trivial stones. More generally, we may gain insights into the dynamics presiding over our evolution only thanks to highly elaborated scientific theories, developed within laboratories and divulged through essays, as famously shown by Bruno Latour and Steve Woolgar (1979) regarding research in neuroendocrinology.

Thus, on the one hand, according to Stiegler, anthropogenesis is a technical process. On the other, according to Derrida, it equates with a new articulation of differrance. Stiegler therefore submits that what constitutes this new structure of non-presence is precisely the emergence of technology or, more exactly, the emergence of a lifeform structurally composing with technologies to survive and thrive. Commenting on Derrida's considerations, Stiegler (1998: 134-142) contends that this event constitutes a "rupture in différance" (1998: 138), "a double différance" (1998: 151) and a "différance of différance" (1998: 177), whose momentum would be underestimated by Derrida, who has never developed a history of the supplement 
to complement its logic by reconstructing the different stages of articulation of the gramme.

The question is the meaning to attribute to the "as such" brought forward by this new stage of différance, and whose pivotal role within Martin Heidegger's interpretation of western metaphysics is scrutinized by Derrida in Of Spirit (1989). The doubling of différance as the emergence of technology, Stiegler argues, amounts to the very possibility of self-consciously thematizing différance as the history of life in general, insofar as the latter is conceivable only starting from a particular organization of the living that is human life as technical life. And indeed, Stiegler (2001) carefully distinguishes between the supplement as "technical" already-there of the past, once present, lived by others and inherited through their artefacts, and the supplement as "absolute" already-there of a past that has never been present, lived by no one, amounting to the inexhaustible retreating of presence into absence, thematized by the logic of the supplement proper. They both are neither fully material instances (i.e., definite, concrete beings) nor fully transcendental apparatuses (i.e., abstract, eternal structures), as they only emerge in their material instantiations but cannot be reduced to them. The absolute past, différance as such, renders the "technical" past possible as the constant supplementation of the finitude of biological memory through nonbiological devices. However, this absolute past may manifest itself and be conceptualized "as such" only thanks to the "technical" past, and they therefore mutually constitute. Technology "refers to the arche-trace, older than any empirical or meta-empirical trace; it refers always to the absolute past. But the absolute past only constitutes itself 'as such' through this referral" (Stiegler, 2001: 263). Différance is not reducible to technology. However, the latter amounts to that articulation of différance that enables us to properly access and experience différance in general through that concrete instantiation of différance constituted by this particular discourse about differance, it is "the condition of the possibility and impossibility of having access to the gramme "as such"” (Stiegler, 2001: 251)—-technology framing every possible human experience, even that of différance and its logic.

This is what Stiegler calls the "hermeneutic privilege" of epiphylogenesis (i.e., life pursued through technology): "I posit that it is starting from the epiphylogenetic trace, the trace that appears with technical life, that it is possible for us to discern the trace that constitutes life in general, and to access it, and not the other way around: this is a phenomenologico existential standpoint in the strict sense, which makes conditions of appearance conditions of what appears [...]. To be able to access the trace that does not emerge from epiphylogenesis, [...] it is necessary to start from epiphylogenesis, on the basis of epiphylogenesis [...]. Therefore, the trace before epiphylogenesis presents itself to us only through epiphylogenesis" (Stiegler, 2020: 86). Thus, anthropogenesis marks a change - and yet one among many othersin the process of individuation of life in general. In the first place, Stiegler (2020) argues, we can reconstruct our own origins and conceptualize the history of life in general as the logic of différance only starting from our present condition, i.e., the relativity of our situated perspective, which is constituted by a given stage of technological development. In the second place, it is possible to conceive of différance as such, i.e., to thematize it and render it the object of a philosophical, political or scientific discourse — without, of course, reducing différance to this discourse — only 
through technologies, that is through the mediation of cognitively embedded artefacts cumulatively triggering, sustaining and driving epiphylogenetic evolution.

Thus, Stiegler wittingly diverges from Derrida's stance, which becomes evident in a dialogue between the two, where Derrida reproaches Stiegler for identifying technology with what constitutes intelligibility (i.e., the explicit thematization of a phenomenon's conditions of possibility and impossibility) while demanding to investigate its specificity nonetheless: "the origin of sense makes no sense. [...] That which bears intelligibility, that which increases intelligibility, is not intelligible [...]. From this standpoint, technics is not intelligible. [...] That which constitutes sense is senseless. This is a general structure. [...] The question does not belong to the field of the questioned" (Derrida, 2002: 108-109). While, on that occasion, Stiegler laconically retorts that technology "constitutes sense if it participates in its construction” (Derrida, 2002: 109), his approach's general aim should become clearer in light of the above. Technology, indeed, grants us access to the horizon of intelligibility consisting in the supplemental retreating of presence into absence (i.e., différance "as such"), without this "general structure" being reducible to technology in general, let alone to some individual technology in particular - contrary to what is contended by Friedrich Kittler (1999: 33-38), for instance, who caustically suggests identifying différance as such with nothing but the gramophone needle. At the same time, since we construct and employ concrete technologies all the time, through our practices we also gain insights into their specificity, each of them moulding our experience and framing a historically situated horizon of intelligibility.

\section{Deconstructionist Criticisms}

Stiegler's interpretation of Derrida's notion of différance has raised some criticisms among commentators. While Richard Beardsworth (1995), Ian James (2010) and Ben Turner (2016) consider his stance as ultimately convergent and compatible with the main tenets of deconstruction, Ben Roberts (2005), for instance, contends that Stiegler unduly identifies what Derrida calls the non-living in general with (human) technology in particular. The latter would rather be only one possible manifestation of the articulation of the living onto the non-living composing différance, and to account for human specificity and the related doubling of différance it implies is nonsensical, insofar as for Derrida the differential relation between the living and the non-living is constitutive of life itself, which is always confronted with metabolic and environmental processes regarding what is other-than-life-starting from air-breathing, for instance. These remarks are shared by Tracy Colony (2011), who also submits that by doing so Stiegler underestimates how animal life is finite and aporetically relating to alterity as much as human life is, thereby compromising himself with the anthropocentric exceptionalism famously denounced by Giorgio Agamben in The Open (2003) and by Derrida himself in The Animal That Therefore I Am (2008). Francesco Vitale (2020), similarly, also points out that Stiegler, instead of inscribing technology within life itself, as Derrida does, refers to it in order to account for human specificity. Moreover, his conception of animal life would disregard Derrida's methodological precautions, insofar as "the animal" as an 
undifferentiated whole is opposed to humanity and conceived of as purely homogeneous automaticity. From a Derridean perspective, Vitale argues, différance differs from itself at each stage of the living, producing a different articulation for every species, rather than a single rupture concerning humans alone.

The interpretation of Stiegler's philosophy of technology I aim to submit here contends a more nuanced scenario. Preliminarily, I aim to stress that one should be careful not to confuse the theory of human constitutive technicity-maintained by Stiegler as well as by other contemporary philosophers such as Roberto Esposito (2011), Peter Sloterdijk (2016) and Carlo Sini (2021)—with the theory of originary technicity purported by some eminent representatives of French thought such as Georges Canguilhem (2008) and Jean-Luc Nancy (2008), and whose theoretical metamorphoses have been recently reviewed by Arthur Bradley (2011). Indeed, to submit that human life is evolutionarily and developmentally structured by technological mediations, and that it could neither emerge nor be conceived of regardless of them, is quite a different claim than to maintain that life in general is never "pure", i.e., self-referentially centred, but rather structurally relates to its other, always haunted by alterity and never acquiring autonomous givenness. As Derrida himself aims to show in Life Death (2020) through a discerning commentary of biologist François Jacob's masterpiece The Logic of Life (1993), to place alterity at the core of life itself may enable us to deconstruct the worn-out, long-lasting dichotomies between nature and culture as well as between humans and animals. However, this deconstructive effort provides us with no insights into the specificity of technology — which is not the very same thing as "originary technicity", but rather represents a particular form of alterity — and its impact on a particular evolutionary trajectory, that is the human lineage.

The main question here is the difference between distinctions and oppositions. While acknowledging that we should not oppose the human to the animal lifeform, Stiegler (2020) maintains that a distinction should be made nonetheless in order to understand the specificity of technical life. Thus, while there is indeed no such a thing as "pure life", life always aporetically relating with its other and articulating itself at each organismic stage according to the ever-changing structures of différance, for Stiegler technologies represent a particular form of alterity and therefore a new articulation of différance. On the one hand, this assumption is consistent with Derrida's approach, who insightfully claims that "everything I'll say will consist, certainly not in effacing the limit [between human and animal lifeforms], but in multiplying its figures, in complicating, thickening, delinearizing, folding, and dividing the line precisely by making it increase and multiply" (Derrida, 2008: 29). The aim of deconstruction is not to eliminate all possible differences between humans and the other animals, but rather to avoid understanding these differences as absolute oppositions, hypostatizing humanity as what would define itself by opposing a likewise hypostatized conception of "the animal" in general. On the other, Stiegler believes that Derrida fails to properly articulate this distinction because he does not give due consideration to technology as what, by marking a new stage of différance, produces the human lifeform.

Importantly, what the abovementioned commentators do not seem to discuss is that Stiegler inscribes Derrida's failure to properly thematize technology within the 
core of deconstruction itself, namely in his criticism of Edmund Husserl's phenomenology. Indeed, in On the Phenomenology of the Consciousness of Internal Time (1991), Husserl opposes what he calls primary memories (or retentions), that is the enchained perceptual moments of the flow of lived experience, to what he calls secondary memories, that is the recollection of past events. Quarrelling with his mentor Franz Brentano, Husserl is concerned with keeping perception (and therefore time perception) absolutely separated from phantasy, in order not to let the former depend on the latter, which he believes would pave the way to idealistic solipsism, i.e., the suspicion that external reality is nothing but a mental phenomenon. In Speech and Phenomena (1973: 45-46), Derrida cogently shows how phenomenological presence, i.e., what Husserl believes to be the originary given of the flow of retentions within consciousness, is always haunted by an absence working through it and depriving it of its plenitude and self-reference. Far from being originary, presence is supplementally deferred according to the logic of différance, presentation always being a re-presentation. Thus, primary and secondary memories, Derrida argues, do not oppose, but rather compose within the movement of différance. According to Stiegler (2009), however, Derrida's criticism of Husserl's opposition of primary to secondary memories results in the effacement of every distinction between the two. This stance is problematic, Stiegler claims, insofar as it prevents Derrida from conceptualizing what Stiegler calls tertiary retentions - that is, as I will discuss below, technology as exosomatized memory.

\section{Biological Criticisms}

Criticisms of Stiegler's philosophy of technology can be raised also from the viewpoint of palaeoanthropology and evolutionary biology. In the first place, it is widely acknowledged that many nonhuman animals, and the other great apes especially, produce and utilize technologies (Bentley-Condit \& Smith, 2010). Particularly, chimpanzees seem capable of constructing their own tools - turning a branch into a rudimental spear by trimming the tip and stripping off the side branches, for instance (Pruetz \& Bertolani, 2007). And at least in captivity, they have been witnessed to show signs of planning and organization regarding tool use, such as caching stones for future throwing (Osvath, 2009). Furthermore, group-specific cultural traditions can be appreciated in a variety of nonhuman animals (Whiten, 2019), and socially learned behaviours are even thought to influence some species' evolution to some extent (Whitehead et al., 2019). In the second place, tool use is dated as back as 3.3 million years ago (Harmand et al., 2015), that is well before the emergence of the genus Homo, which separated from the other Hominins around 2.5 million years ago.

Thus, technology is not something pertaining to humans alone, as Stiegler (2014: 33) still seems to suggest at times, claiming that nonhuman life would abide by "an economy of the instincts, which control animal behaviour with the rigour of automatism" (Stiegler, 2016: 22)—perhaps overly relying on a far from straightforward concept such as that of instinct (Bateson, 1987) and thereby risking falling prey to Derrida's (2008: 83-84) criticism of the metaphysical conceptions understanding 
animal behaviour as strictly determined by (genetic) programmes. However, regarding the production, utilization and transmission of artefacts, the extent of the pervasiveness and indispensability of technology in nonhuman animals, as well as its potential for becoming cumulative and eventually taking over their processes of speciation, is not ascertained. Furthermore, scholarship in ethology does not seem to thematically relate cultural transmission and social learning, on the one hand, to the use, production and transmission of tools, on the other, whereas it has been suggested that precisely the socially driven manufacture of tools, in Hominins, would trigger the so-called "ratchet effect" driving anthropogenesis: "cumulative cultural evolution takes place when the inventions in a cultural group are passed on with such fidelity that they remain stable in the group until a new and improved invention comes along", as contended by the developmental psychologist Michael Tomasello (2014: 121).

In the third place, current scholarship in evolutionary biology recognizes the existence of nuanced and multifarious systems of nongenetic inheritance and transgenerational transmission of behaviours (Haidle et al., 2015; Jablonka \& Lamb, 2006). As reviewed by Heard and Martienssen (2014), transgenerational epigenetic inheritance, i.e., the stable transmission of mutations in gene expression not involving changes in DNA, actually occurs in plants and at least some animals. This account does not abide by a pure Lamarckian conception of biological inheritance of acquired traits, as the adaptive function of these mutations and the role played by the environment in these processes are not clear and perhaps unlikely. However, the relationship between genetic programming and developmental experience may not be one of complete incommunicability, as Stiegler (2010: 206) still tends to maintain. While Michael Haworth (2015), for instance, goes so far as to claim that these scientific finds may jeopardize the validity of Stiegler's conception of epiphylogenesis as a novel process within biological evolution enabling the transgenerational inheritance of developmentally acquired experience through technologies, I believe that this is not the case, since, in the first place, transgenerational epigenetic inheritance is not ascertained in mammals, let alone in humans. In the second place, what matters from Stiegler's perspective is that technical evolution, once it becomes systemic and cumulative, radically influences the process of speciation, producing a lifeform structurally composing with technologies for its survival-a circumstance that none of the studies reviewed by Haworth seems to mention.

Importantly, Stiegler emphatically contends that "the issue is not that of the human' but of the process of which it serves as the transmitter" (Stiegler, 2008b: 255): other animals may well adopt technologies and transgenerationally transmit the acquisitions of their lived experience. Indeed, Stiegler thoroughly problematizes the category of the human, so that the question here is not so much that of the definition of humans as a (biological) species than that of the process of transmission of experience through technology in general. Rather than conceiving of technology as a means to determine human specificity, Stiegler is concerned with understanding technology in itself as what enables a new articulation of the living onto the non-living, i.e., a new lifeform as a new stage of différance. As I will discuss below with reference to postphenomenology, the mutual constitution of humans and technologies contended by Stiegler enables him to avoid the risks of a deterministic 
essentialism by the side of both terms. On the one hand, indeed, one cannot think of humans regardless of how technologies contribute to shaping both our biology and our understanding of our biology. On the other, one cannot think of technologies regardless of their intertwinements with the human lifeform and cognition.

\section{Stiegler's Definition of Technology}

After this detour through evolutionary biology and anthropology, let me now get back to Stiegler's confrontation with Derrida's thought by introducing the fundamental concept of pharmacology. As discussed by Derrida in Plato's Pharmacy (1981), the ancient Greek word pharmakon conveys the sense of the supplemental logic of différance: signifying both remedy and poison, it originally refers to medicinal and magical draughts. Subsequently, its meaning has been extended by Plato to conceptualize the ambiguous character of writing in relation to memory. According to Derrida, pharmaka "can be-alternately or simultaneously-beneficent or maleficent" (Derrida, 1981: 70). Indeed, this is evident in the case of writing: while bestowing our finite, biological memory on external, artificial supports, we enlarge it. At the same time, however, we also reduce it, because what is bestowed on writing is also expropriated from our neuro-somatic intimacy and transferred to the collectivized world of artefacts. Negatively understood, as Plato does, "contrary to life, writing —or, if you will, the pharmakon-can only displace or even aggravate the ill. [...] Under pretext of supplementing memory, writing makes one even more forgetful; far from increasing knowledge, it diminishes it" (Derrida, 1981: 100): writing is deemed to strengthen hypomnesis (recollection) at the expense of anamnesis (living awareness of actual experience). However, as argued by Derrida, the pharmakon is not purely negative: writing, as a historical instance of arche-writing, i.e., the differential movement of the trace, partakes in the very structure of Being, always ambiguous and irreducible, both producing and amounting to continuous deferrals and differentiations.

In What Makes Life Worth Living (2013), Stiegler appropriates Derrida's notion of pharmakon, stating that all artefacts are pharmaka, technology, as an articulation of différance, being essentially pharmacological. The complex of human technologies "is at once what enables care to be taken and that of which care must be taken-in the sense that it is necessary to pay attention: its power is curative to the immeasurable extent that it is also destructive" (Stiegler, 2013: 4). Consequently, pharmacology is "a discourse on the pharmakon understood in the same gesture in its curative and toxic dimensions" (Stiegler, 2013: 4). I submit that two interdependent meanings of the pharmacological function of technology may be singled out. In the first place, technology is what should be taken care of by a collective, i.e., what both needs care and provokes concern: on the one hand, organologically, humans can survive and thrive only through their institutionally socialized artefacts, whose modes of employment should therefore be explicitly regulated and administered. On the other, technical innovations trigger a suspension of the extant behavioural patterns and lifeways, requiring and provoking their modification. The rearrangement of the modes of life peculiar to a given epoch and region, elicited by technological 
change, may either be actively pursued, appropriated and collectively determined, or passively undergone, inadvertently withstood and accepted. In the first case, Stiegler argues, it engenders a comprehensive and coherent reconfiguration of the patterns of individual and collective existence-what he terms double epokhal redoubling (Stiegler, 2008b: 242). In the second case, it provokes social fragmentation, unaware behavioural automatization, eventually leading to a cultural breakdown.

In the second place, pharmacology also refers to the increasing functional rearrangement technologies engender while constituting the human lifeform, starting from anthropogenesis. Our organological constitution, Stiegler claims, "is constantly and has forever been challenged and called into question by a technicity that is itself perpetually new. From the moment of its default of origin, this being has continued to develop ways of compensating for the perverse, secondary effects of its primordial technicity" (Stiegler, 2013: 113-114). Technical apparatuses evolve and thereby restructure our psychophysical and behavioural constitution, letting it evolve in turn. However, while our technologies enable us to expand, refine or redirect our organic functions, disclosing new possibilities of subjectivation, shared lifeways and organizations of survival, by doing so we also delegate to technologies what was formerly performed by biological organs. This has two main, interconnected consequences. Firstly, evolving technologies, since they are socialized, i.e., inscribed within organological collectives, always entail the rearrangement of the tasks and duties devoted to their employment: the social organizations presiding over their acquisition, reproduction and maintenance shall change according to the technological systems they deal with. Secondly, technological evolution engenders the reconfiguration of the biological organs that formerly performed these functions: from supports of organic functions, these organs become supports of the technologies exerting these functions in their place (but not without their contribution), therefore becoming supports of supports, losing some capabilities and acquiring others. This leads to an increasingly mediated relationship with the environment, since artificialization calls for further artificialization, according to the logic of artificial selection discussed above.

Yet what does Stiegler exactly mean when he speaks about technologies as pharmaka? I believe that three, interconnected and complementary definitions are submitted throughout his work. In the first place, technology is understood as "organized inorganic matter" (Stiegler, 1998: 49). While the living is organic, organized matter and the non-living is inorganic, unorganized matter, technologies are halfway between them, inorganic and yet organized matter, evolving partly according to their own dynamics, an interstitial and irreducible third between physics and biology, thereby mediating human relation with the environment. One may object that technologies are not forcefully made out of inorganic matter-as wood or leather instruments, for instance-and that also "physical" matter presents forms of organization-such as crystals, famously analysed by Simondon in Individuation in Light of Notions of Form and Information (2020: 77-87). However, I believe that the emphasis in Stiegler's discourse lays in the process of organization rather than in its outcome, as technologies do not organize spontaneously from themselves (as living and even non-living beings are supposed to do), do not self-constitute, but are 
rather produced by something else, which they nonetheless contribute to producing in return.

This remark leads us to Stiegler's second definition of technology. Following Leroi-Gourhan's (1993) terminology in the three published volumes of Technics and Time (1998, 2008b, 2010), he defines technology as the exteriorization of life outside itself, i.e., in the other-than-life: "as a 'process of exteriorization,' technics is the pursuit of life by means other than life" (Stiegler, 1998: 17). In light of the above, we should be careful to specify that this amounts to only one possible relation of the living with the non-living, according to the supplemental logic of différance inscribing alterity at the core of identity_and yet, only by drawing our attention to this particular relation we may become capable of accounting for anthropogenesis, i.e., our own origins.

Contrary to biological organs, technologies are detachable organs, as Stiegler (2008a: 30-31) points out in the wake of Simondon's (2016: 67-71) and LeroiGourhan's (1993: 234-235) analyses. In his later works, such as The Age of Disruption (2019), he prefers the term exosomatization, i.e., the production of artificial (extrabodily) organs, to refer to the same phenomenon, thereby adopting insights coming from the mathematician Alfred Lotka (1945) and the economist Nicholas Georgescu-Roegen (1977). The logic of this process is paradoxical, insofar as there is no interiority (e.g., soul, spirit, mind etc.) which would subsequently exteriorize itself; rather, one should "speak of an exteriorization without a preceding interior: the interior is constituted in exteriorization. [...] The interior and the exterior are the same thing [...] since man (the interior) is essentially defined by the tool (the exterior)" (Stiegler, 1998: 141-142). Technologies as exosomatic organs subsist independently of the individuals who produced them, surviving their biological death and becoming collectively and transgenerationally transmissible. Other individuals may acquire, adopt and modify them-thereby inheriting the knowledge of their usage and production inscribed within them as trails of the experience of those who made and utilized them-and eventually, in turn, transmit this exosomatized knowledge to posterity, pursuing epiphylogenesis further.

One may object that also a biological organ may be detached, survive its owner's death and be passed on to others, as is the case for a transplanted kidney or a scalp, for instance, although this may only occur provided that the biological organ is inscribed within a complex of technologies providing for its "artificialization" and enabling its detachability. Reciprocally, artificial organs are not always properly detachable, like tattoos, whose eradication from their bearers would amount to their destruction, or pacemakers, whose removal would most likely elicit their owners' death. However, I believe that the emphasis should go once again on the process of exosomatization rather than on its outcome: the appropriation or dispossession of an artefact amounts more to the loss or acquisition of a function than to the physical displacement of an object. For instance, while a visually impaired person can remove her eyeglasses without incurring sudden death, in the present stage of technological development that would immediately transform her relation to the world to the point that it is no longer the same as it was when she was wearing them.

The process of exosomatization therefore performs the organization of "inorganic", that is nonbiological matter, and the reorganization of biological matter. And 
in my view, this emphasis on the process lays at the core of Stiegler's third definition of technology as well, i.e., tertiary retention. Starting from the commentary on Husserl's theory of time perception that I have sketched out above, Stiegler (2008b: 188-243) conceives of technologies as a third form of memory, which combines itself with primary and secondary memories while supplementing individual, nervous memory and collective, genetic memory in the evolutionary process of epiphylogenesis. While the two biological memories are inscribed within the nervous system and the genetic code respectively, technical memory is inscribed within artefacts. Indeed, Stiegler argues, instruments retain within them the knowledge necessary to their production and usage, which is engraved within their very texture, shape and composition. A tool is therefore exosomatized memory, the trace of the experience of those who produced and utilized it. While this conception may result quite evident with respect to something like a book, also a chipped stone, for instance, preserves in its structure the gestural sequences and operations devoted to its production and employment: "the stereotype is as much the result as the condition of its production, both the support of the memory of operational sequences that produces it, conserving the trace of past epigenetic events that accumulate as lessons of experience, and the result of the transmission of these operational sequences by the very existence of the product as an archetype" (Stiegler, 1998: 177). Monuments are artefacts referring to events that often occurred long before the people who admire them (or tear them down) were born-and still, they convey to us an experience of these events as they were lived by those who commissioned their construction.

Thus, Stiegler claims, the organisms performing exosomatization render part of their lived experience available to others also regardless of their actual presence and even survival, contrary to biological memories, which are bound to the living individuals embodying them. Crystallized within artefacts, our knowledge may be passed on to other individuals across multiple generations, cumulating with other artefactually inscribed knowledge and rearranged according to the individual experience of those inheriting it, evolutionarily growing in importance to the point of actually constituting human capabilities to recall and anticipate: a tertiary retention is "a compensation that not only acts as a support when it [i.e., biological memory] 'flinches' but that establishes it in its originary possibility" (Stiegler, 2008b: 220). From this viewpoint, every support of inscription-even air, as the support of vocal communication-be it organic or inorganic, partially or completely detachable or not, may serve as mnestic support, insofar as it is embedded with a lived experience and is able to retain, preserve and transmit it to others.

From this perspective, I aim to stress that these definitions of technology draw our attention to the performance of the process of mnestic transmission, where artefacts compose with the nervous memory of other individuals and, while partaking in their artificial environment, influence the selection of their genetic memory. Stiegler refers to "the tertiary retentions originarily constitutive of technical objects (inasmuch as they are epiphylogenetic)" (Stiegler, 2014: 69, my emphasis): something is a technology only insofar as it partakes in epiphylogenesis, i.e., as it constitutes new organological articulations between biological organs, artificial organs and social organizations. Thus, I submit that Stiegler's definition of technology is functional rather than substantial: it does not seek to establish a general criterion apt to assess 
a priori whether a given being should be conceived of as technology or not. It rather fosters us to understand technologies as something occurring within the process of organological individuation amounting to the human (and possibly also nonhuman) lifeform as technical life: "tertiary retentions are only active, however, and can only constitute this kind of support, on the condition that they are practised" (Stiegler, 2015: 107) through apprenticeships, rituals, pedagogies etc. Only insofar as they perform the nonbiological transmission of memory while composing with biological memory at the same time, tertiary retentions are "activated" and therefore serve as technologies.

\section{Postphenomenology and General Organology}

In light of the above, having clarified Stiegler's understanding of technology with special reference to Derrida's intellectual legacy, I believe that it becomes possible to scrutinize the affinities and divergences between postphenomenology and Stiegler's approach, in order to foster a dialogue between contemporary philosophy of technology and the French thought. Currently, a debate between these two eminent philosophical approaches to the study of technology seems limited to a two-day workshop that took place at Radboud University, Nijmegen, in 2018, followed up by a special issue of Foundations of Science edited by Pieter Lemmens and Yoni van den Eede in 2021. Thus, what follows aims to elaborate and expand upon the main results of this preliminary confrontation.

The theoretical stance contended by Ihde and Verbeek understands technology through the key concept of multistability (Ihde, 1990: 144-151), i.e., the fact that a given artefact may assume very different functions and meanings according to the social milieu where it is employed and the context of usage of its employment, thus becoming quite a different artefact each time (Rosenberger \& Verbeek, 2015). For instance, an umbrella is usually used as a means to protect oneself from the rain or the sun, but can also serve as a rudimental weapon, if needed. Less prosaically, a totem pole operating as a devotional device in one culture may become the object of a museum exposition in another. As Ihde claims regarding printing, "the point is that the same technology [...] can be and is differently embedded and has multiple "histories"" (Ihde, 2010: 127). Through the concept of multistability, Ihde and Verbeek aim to overcome technological determinism and essentialism, i.e., the presupposition that technological evolution follows a predetermined, teleologically oriented trajectory, and that technology can be defined according to some ahistorical, aprioristically established criterion.

Notably, the notion of multistability has been widely implemented within postphenomenological literature (e.g., Irwin, 2016; Wellner, 2016), and since Ihde's seminal formulation it has also undergone in-depth theoretical scrutiny. Indeed, attention has been drawn to the different ways according to which multistability manifests itself, interrelating with the various instances of technological mediation (Whyte, 2015) as well as changing according to regions and epochs (Wellner, 2020). Moreover, as pointed out by Heather Wiltse (2020), in at least some technologies the multistable character is due to the polyfunctionality of the artefact itself, rather than 
solely depending on the modes of employment it undergoes. Finally, as highlighted by Bas de Boer (2021), also the environment plays a role in configuring different utilizations of the same device. Thus, the function of a technology is not simply determined by its use but is rather the outcome of a complex intersectional process involving the diverse subjects utilizing it, the sociocultural environment of its employment and the very structure of the artefact.

Importantly, the concept of multistability amounts to a functional definition of technology, insofar as the status of a given artefact is determined before, during and after its use, which is always historical, context-dependent and plural. As I have discussed above, also Stiegler's definition of technology is functional. Something is technical only insofar as it serves as tertiary memory, i.e., as exosomatized experience composing with the individual, nervous memory and the collective, genetic memory in order to pursue epiphylogenetic evolution, that is the emergence of a new organological arrangement of artificial organs, biological organs and social organizations. In this sense, Stiegler's stance prompts us to bring the concept of multistability to its extremes: while no a priori definition of what a technology is regardless of its context of usage can be given, technologies can become very different things according to how they are employed - and even cease to be technologies altogether, if their capability to nonbiologically transmit memory while composing with biological memory breaks down.

Let me now take this interpretation one step further. The so-called empirical turn in philosophy of technology (Achterhuis, 2001) endorsed by the postphenomenological approach criticizes traditional philosophies of technologies-exemplified by stances such as Heidegger's (1977) and Jacques Ellul's (1964)—claiming that individual, empirical technologies are not fully determined by their transcendental conditions of existence and that therefore there is no inner teleology within technical evolution, which is rather a contingent, context-dependent process. Traditional philosophies of technology are deemed to be overly pessimistic, deterministic and abstract in their understanding of technology, as contented by Philip Brey (2010), thereby reproducing the traditional divide between a transcendental, that is abstract, disincarnated and ahistorical subject, and the empirical multiplicity of worldly experience. Within metaphysical thinking, the transcendental subject would constitute its world by framing the given of experience, without being modified by this given in return. According to philosophers such as Heidegger and Ellul, "technology" would occupy the place of the traditional transcendental subject, insofar as it is considered an atemporal, all-encompassing force driving human development by some inner principle of increasing perfectibility, performativity or pervasiveness. Human subjects, now displaced on the side of the empirical, would therefore be deprived of every agency, powerlessly witnessing the relentless takeover of the global technical system.

Importantly, as contended by Lemmens (2021), while postphenomenology gets rid of the empirical-transcendental question altogether, Stiegler aims to reframe it in order to keep the relation between what constitutes and what is constituted open, without falling prey to an essentialist, teleological metaphysics at the same time. Moreover, as discussed by van den Eede (2021), in this debate one should not irretrievably counterpose a fierce defence of the transcendental to its complete 
abandonment, but rather emphasize the interdependency and mutual beneficiality of the two approaches. Indeed, Stiegler does not advocate for an empirical-transcendental divide where technology would occupy the place of any one of the terms and humans the other. Human constitutive technicity rather prompts us to consider humans as biotechnological hybrids, our biology being both phylogenetically and ontogenetically rearranged by the technologies we in turn concur to produce. Thus, Stiegler's approach aims precisely to question the validity of the traditional ways of framing this dilemma, as Michael Lewis (2013) points out.

Stiegler's conception of human constitutive technicity seems to fit in well with what Verbeek (2008) contends in a pivotal paper, where he expands upon Ihde's four forms of human-technology relations by singling out a fifth form, what he terms cyborg relation. According to Ihde (1990), indeed, embodiment relations represent the combination of human and technological intentionality. However, cyborg relations, Verbeek claims, constitute a form of intentionality where a distinction between what is human and what is technological cannot be made anymore, thereby representing a new kind of entity, what he calls hybrid intentionality. In these cases, humans and technologies are completely merged, actually constituting a new organism, which Verbeek (2011: 139-152), interpreting Donna Haraway's (1991) seminal analyses, understands as the outcome of contemporary technological developmentexemplified by psychopharmacological drugs or nanotechnological implants. As pointed out by Paul B. Preciado, who also elaborates on Haraway's insights, "this is the age of soft, featherweight, viscous, gelatinous technologies that can be injected, inhaled-'incorporated"' (Preciado, 2013: 77). In the wake of Lemmens's (2017) analyses, I submit that Verbeek's concept of hybrid intentionality is convergent with what Stiegler means when he speaks about human life as technical life, except that he considers it to be the originary condition of possibility of the human lifeform as a whole, and not the acquisition of a later, localized stage of technological development. Interestingly, recent research in postphenomenology seems to increasingly acknowledge the originary technical condition of the human lifeform, emphasizing the role played by technologies throughout anthropogenesis (Ihde \& Malafouris, 2019).

In conclusion, I believe that this comparison with postphenomenology may enable us to better understand the difference between Stiegler's stance and the interpretation of the main tenets of deconstruction purported by "orthodox" representatives of French thought. According to Geoffrey Bennington's (1996) criticism of Stiegler's appropriation of Derrida's thinking, for instance, "the possibility of the 'appearing as such' of the gramme is built into the description of the trace quite independently of the factual history of the emergence of mankind or any other species" (Bennington, 1996: 189-190, my emphasis), i.e., the movement of differance cannot be influenced by any empirical event. Here différance is conceived of as a transcendental metalogic of Being, articulating empirical becoming without being impacted by the latter to any extent. Thus, while I acknowledge that postphenomenology is right in criticizing such an understanding of the empirical-transcendental divide, I also believe to have shown that Stiegler's approach should not be considered representative of this stance, but rather amounts to a criticism of this very same understanding. 
The place of the transcendental, Stiegler argues, is occupied neither by an abstract human subject nor by a monolithic technical system. Technologies are rather what he calls a-transcendental (Stiegler, 2008b: 222): they constitute the human lifeform, shaping our evolutionary trajectory as well as our daily experience, amounting to the conditions of possibility (and impossibility) of our existence as well as our capability to thematize them as such, i.e., conceiving of them in their specificity and developing a discourse about technologies. At the same time, humans constitute the individual technologies, which are the products of our socially embedded and culturally transmitted practices. Thus, what constitutes is constituted in turn by what it constitutes in a recursive, processual logic.

According to Stiegler's perspective, technology operates at both an empirical and a transcendental level: on the one hand, it constitutes the horizon of experience enabling the evolution and development of human life and thought, determining our modalities of subjectivation and possibilities to invent alternatives. On the other, it is not some disincarnated, atemporal entity, but it rather consists in nothing else than the individual, concrete and historical technologies each time determining a given cultural context. To state that technology frames our existence does not mean that our lives are governed by some invisible, impersonal force. It means that the human lifeform could neither evolutionarily emerge nor be conceived of without the moulding effects of technologies on our biology. Since these technologies are always historical and multistable, the human lifeform does not follow a predetermined path but is rather relatively free to compose and negotiate with technologies in novel forms, thereby producing multifarious lifeways.

This relative freedom, however, should not be conceived of as an irrevocable given, insofar as it is in turn constructed according to the possibilities of subjectivation offered by the different, historical technologies - each one endowed with a specific form of intentionality, as Ihde points out (1990: 139-144). As argued by Agostino Cera (2020), while the technological essentialism purported by thinkers such as Heidegger and Ellul should be rightly dismissed, the empirical turn in philosophy of technology risks neglecting the question concerning technology altogether, insofar as it underestimates how technologies contribute to shaping our worldly experience also negatively. Indeed, their multistable polyvalence, combined with their evolutionarily constitutive relevance, means that technologies not only constitute our capability to think - and to think about technology, especially — but may also destitute us from this capability, rendering thinking actually impossible-a remark emphatically made by Stiegler himself (2018). And as I have shown above, this insight is at the heart of Stiegler's (2016: 292) pharmacology: technology constantly calls humans into question, on the one hand, as the ineliminable possibility of social breakdown provoked by disruptive technological changes when not adequately taken care of. On the other, as the standing reorganization of our extant biological functions through their bestowal on artificial organs.

Acknowledgements The author wishes to thank Gerald Moore and Michael Lewis, as well as two anonymous reviewers, for their insightful comments on an earlier version of this article.

Data Availability Not applicable. 
Code Availability Not applicable.

\section{Declarations}

Conflict of Interest The author declares no competing interests.

Open Access This article is licensed under a Creative Commons Attribution 4.0 International License, which permits use, sharing, adaptation, distribution and reproduction in any medium or format, as long as you give appropriate credit to the original author(s) and the source, provide a link to the Creative Commons licence, and indicate if changes were made. The images or other third party material in this article are included in the article's Creative Commons licence, unless indicated otherwise in a credit line to the material. If material is not included in the article's Creative Commons licence and your intended use is not permitted by statutory regulation or exceeds the permitted use, you will need to obtain permission directly from the copyright holder. To view a copy of this licence, visit http://creativecommons.org/licen ses/by/4.0/.

\section{References}

Achterhuis, H. (2001). Introduction: American philosophers of technology. In H. Achterhuis (Ed.), American philosophy of technology: The empirical turn (pp. 1-9). Indiana University Press.

Agamben G. (2003). The open: Man and animal. Stanford University Press.

Bateson G. (1987). Metalogue: What is an instinct?. In G. Bateson (Ed.), Steps to an ecology of mind: Collected essays in anthropology, psychiatry, evolution, and epistemology (2nd ed., pp. 48-69). Aronson.

Beardsworth, R. (1995). From a genealogy of matter to a politics of memory: Stiegler's thinking of technics. Tekhnema, 2, 85-115.

Bennington, G. (1996). Emergencies. Oxford Literary Review, 18(1), 175-216.

Bentley-Condit, V. K., \& Smith, E. O. (2010). Animal tool use: Current definitions and an updated comprehensive catalog. Behaviour, 147(2), 185-221.

de Boer, B. (2021). Explaining multistability: Postphenomenology and affordances of technologies. AI \& Society.

Bradley, A. (2011). Originary technicity: The theory of technology from Marx to Derrida. Palgrave Macmillan.

Brey, P. (2010). Philosophy of technology after the empirical turn. Techné: Research in Philosophy and Technology, 14(1), 36-48.

Canguilhem, G. (2008). Machine and organism. In G. Canguilhem (Ed.), Knowledge of life (pp. 75-97). Fordham University Press.

Cera, A. (2020). Beyond the empirical turn: Elements for an ontology of engineering. Információs Társadalom, 20(4), 74-89.

Colony, T. (2011). Epimetheus bound: Stiegler on Derrida, life, and the technological condition. Research in Phenomenology, 41(1), 72-89.

Derrida, J. (1981). Plato's pharmacy. In J. Derrida (Ed.), Dissemination (pp. 63-171). University of Chicago Press.

Derrida, J. (1982). Différance. In J. Derrida (Ed.), Margins of philosophy (pp. 3-27). University of Chicago Press.

Derrida, J. (2020). Life death. University of Chicago Press.

Derrida, J. (1973). Speech and phenomena and other essays on Husserl's theory of signs. Northwestern University Press.

Derrida, J. (1989). Of spirit: Heidegger and the question. University of Chicago Press.

Derrida, J. (1997). Of grammatology (2nd ed.). John Hopkins University Press.

Derrida, J. (2002). Echographies of television: Filmed interviews with Bernard Stiegler. Wiley.

Derrida, J. (2008). The animal that therefore I am. Fordham University Press.

van den Eede, Y. (2021). Thing-transcendentality: Navigating the interval of 'technology' and 'Technology'. Foundations of Science. 
Ellul, J. (1964). The technological society. Vintage Books.

Esposito, R. (2011). Politics and human nature. Angelaki: Journal of the Theoretical Humanities, 16(3), 77-84.

Feenberg, A. (2002) Transforming technology: A critical theory revisited. Oxford University Press.

Georgescu-Roegen, N. (1977). Inequality, limits and growth from a bioeconomic viewpoint. Review of Social Economy, 35(3), 361-375.

Hägglund, M. (2011). The arche-materiality of time: Deconstruction, evolution and speculative materialism. In J. Elliott \& D. Attridge (Eds.), Theory after 'theory' (pp. 265-277). Routledge.

Haidle, M. N., Bolus, M., Collard, M., Conard, N. J., Garofoli, D., Lombard, M., Nowell, A., Tennie, C., \& Whiten, A. (2015). The nature of culture: An eight-grade model for the evolution and expansion of cultural capacities in Hominins and other animals. Journal of Anthropological Sciences, 93, 43-70.

Haraway, D. (1991). A cyborg manifesto: Science, technology, and socialist-feminism in the late twentieth century. In D. Haraway (Ed.), Simians, cyborgs and women: The reinvention of nature (pp. 149-181). Routledge.

Harmand, S., Lewis, J. E., Feibel, C. S., Lepre, C. J., Prat, S., Lenoble, A., et al. (2015). 3.3-million-yearold stone tools from Lomekwi 3, West Turkana, Kenya. Nature, 521, 310-315.

Havelange, V., Lenay, C., \& Stewart, J. R. (2002). Les représentations : Mémoire externe et objets techniques. Intellectica, 35(2), 115-129.

Haworth, M. (2016). Bernard Stiegler on transgenerational memory and the dual origin of the human. Theory, Culture \& Society, 33(3), 151-173.

Heard, E., \& Martienssen, R. A. (2014). Transgenerational epigenetic inheritance: Myths and mechanisms. Cell, 157(1), 95-109.

Heidegger, M. (1977). The question concerning technology. In M. Heidegger (Ed.), The question concerning technology and other essays (pp. 3-35). Garland.

Hui, Y. (2016). The question concerning technology in China: An essay in cosmotechnics. Urbanomic.

Husserl, E. (1991). On the phenomenology of the consciousness of internal time (1893-1917). Springer.

Ihde, D. (1979). Technics and praxis. Reidel.

Ihde, D. (1990). Technology and the lifeworld: From garden to earth. Indiana University Press.

Ihde, D. (2010). Heidegger's technologies: Postphenomenological perspectives. Fordham University Press.

Ihde, D., \& Malafouris, L. (2019). Homo faber revisited: Postphenomenology and material engagement theory. Philosophy \& Technology, 32(2), 195-214.

Irwin, S. O. (2016). Digital media: Human-technology connection. Lexington Books.

Jablonka, E., \& Lamb, M. J. (2006). The evolution of information in the major transitions. Journal of Theoretical Biology, 239(2), 236-246.

Jacob, F. (1993). The logic of life: A history of heredity. Princeton University Press.

James, I. (2010). Bernard Stiegler and the time of technics. Cultural Politics, 6(2), 207-228.

Jasanoff, S. (2019). Can science make sense of life? Wiley.

Kapp, E. (2018). Elements of a philosophy of technology: On the evolutionary history of culture. University of Minnesota Press.

Kittler, F. (1999). Gramophone, film, typewriter. Stanford University Press.

Latour, B., \& Woolgar, S. (1979). Laboratory life: The social construction of scientific facts. SAGE Publishing.

Latour, B. (2005). Reassembling the social: An introduction to actor-network-theory. Oxford University Press.

Lemmens, P. (2017). Thinking through media: Stieglerian remarks on a possible postphenomenology of media. In Y. van den Eede, S. O. Irwin, G. Wellner, \& D. Ihde (Eds.), Postphenomenology and media: Essays on human-media-world relations (pp. 185-206). Lexington Books.

Lemmens, P. (2021). Thinking technology big again: Reconsidering the question of the transcendental and 'Technology with a Capital T' in the light of the Anthropocene. Foundations of Science.

Leroi-Gourhan, A. (1993). Gesture and speech. MIT Press.

Lewis, M. (2013). Of a mythical philosophical anthropology: The transcendental and the empirical in Technics and Time. In C. Howells \& G. Moore (Eds.), Stiegler and Technics (pp. 53-68). Edinburgh University Press.

Loeve, S., Guchet, X., \& Bensaude Vincent, B. (2018). Is there a French philosophy of technology? General introduction. In S. Loeve, X. Guchet \& B. Bensaude Vincent (Eds.), French philosophy of technology: Classical readings and contemporary approaches (pp. 1-20). Springer. 
Lotka, A. J. (1945). The law of evolution as a maximal principle. Human Biology, 17(3), 167-194.

Malafouris, L. (2013). How things shape the mind. MIT Press.

Moore, G. (2017). On the origin of aisthesis by means of artificial selection; Or, the preservation of favored traces in the struggle for existence. Boundary 2, 44(1), 191-212.

Nancy, J.-L. (2008) Corpus. Fordham University Press.

Osvath, M. (2009). Spontaneous planning for future stone throwing by a male chimpanzee. Current Biology, 19(5), 190-191.

Parrochia, D. (2009). French philosophy of technology. In A. Brenner \& J. Gayon (Eds.), French studies in the philosophy of science: Contemporary research in France (pp. 51-70). Springer.

Preciado, P. B. (2013). Testo junkie: Sex, drugs, and biopolitics in the pharmacopornographic era. The Feminist Press.

Pruetz, J. D., \& Bertolani, P. (2007). Savanna chimpanzees, Pan troglodytes verus, hunt with tools. Current Biology, 17(5), 412-417.

Roberts, B. (2005). Stiegler reading Derrida: The prosthesis of deconstruction in technics. Postmodern Culture, 16(1).

Rosenberger, R., \& Verbeek, P.-P. (2015). A field guide to postphenomenology. In R. Rosenberger \& P.-P. Verbeek (Eds.), Postphenomenological investigations: Essays on human-technology relations (pp. 9-42). Lexington Books.

Simondon, G. (2016). On the mode of existence of technical objects. University of Minnesota Press.

Simondon, G. (2020). Individuation in light of notions of form and information. University of Minnesota Press.

Sini, C. (2021). Machine, Culture, and Robot. In S. Chiodo \& V. Schiaffonati (Eds.), Italian philosophy of technology: Socio-cultural, legal, scientific and aesthetic perspectives on technology (pp. 83-88). Springer.

Sloterdijk, P. (2016). The domestication of being: The clarification of the clearing. In P. Sloterdijk (Ed.), Not saved: Essays after Heidegger (pp. 89-148). Wiley.

Sterelny, K. (2012). The evolved apprentice: How evolution made humans unique. MIT Press.

Stiegler, B. (1998). Technics and time 1: The fault of Epimetheus. Stanford University Press.

Stiegler, B. (2001). Derrida and technology: Fidelity at the limits of deconstruction and the prosthesis of faith. In T. Cohen (Ed.), Jacques Derrida and the humanities: A critical reader (pp. 238-270). Cambridge University Press.

Stiegler, B. (2008a). Économie de l'hypermatériel et psychopouvoir : Entretiens avec Philippe Petit et Vincent Bontems. Mille et une Nuits.

Stiegler, B. (2008b). Technics and time 2: Disorientation. Stanford University Press.

Stiegler, B. (2009). The magic skin; Or, the Franco-European accident of philosophy after Jacques Derrida. Qui Parle, 18(1), 97-110.

Stiegler, B. (2010). Technics and time 3: Cinematic time and the question of malaise. Stanford University Press.

Stiegler, B. (2018). What is called caring? Thinking beyond the Anthropocene. In B. Stiegler (Ed.), The Neganthropocene (pp. 188-270). Open Humanities Press.

Stiegler, B. (2013). What makes life worth living: On pharmacology. Wiley.

Stiegler, B. (2014). Symbolic misery 1: The hyperindustrial epoch. Wiley.

Stiegler, B. (2015). Symbolic misery 2: The katastrophé of the sensible. Wiley.

Stiegler, B. (2016). Automatic society 1: The future of work. Wiley.

Stiegler, B. (2019). The age of disruption: Technology and madness in computational capitalism. Wiley.

Stiegler, B. (2020). Elements for a general organology. Derrida Today, 13(1), 72-94.

Tomasello, M. (2014). A natural history of human thinking. Harvard University Press.

Turner, B. (2016). Life and the technical transformation of différance: Stiegler and the noopolitics of becoming non-inhuman. Derrida Today, 9(2), 177-198.

Verbeek, P.-P. (2008). Cyborg intentionality: Rethinking the phenomenology of human-technology relations. Phenomenology and the Cognitive Sciences, 7(3), 387-395.

Verbeek, P.-P. (2005). What things do: Philosophical reflections on technology, agency, and design. Pennsylvania State University Press.

Verbeek, P.-P. (2011). Moralizing technology: Understanding and designing the morality of things. University of Chicago Press.

Vitale, F. (2020). Making the différance: Between Derrida and Stiegler. Derrida Today, 13(1), 1-16.

Wellner, G. P. (2016). A postphenomenological inquiry of cell phones: Genealogies, meanings, and becoming. Lexington Books. 
Wellner, G. P. (2020). The multiplicity of multistabilities: Turning multistability into a multistable concept. In G. Miller \& A. Shew (Eds.), Reimagining philosophy and technology, reinventing Ihde (pp. 105-122). Springer.

Whitehead, H., Laland, K. N., Rendell, L., Thorogood, R., \& Whiten, A. (2019). The reach of geneculture coevolution in animals. Nature Communications, 10(2405), 1-10.

Whiten, A. (2019). Cultural evolution in animals. Annual Review of Ecology, Evolution, and Systematics, $50(1), 27-48$.

Whyte, K. P. (2015). What is multistability? A theory of the keystone concept of postphenomenological research. In J. K. B. O. Friis \& R. P. Crease (Eds.), Technoscience and postphenomenology: The Manhattan Papers (pp. 69-81). Lexington Books.

Wiltse, H. (2020). Revealing relations of fluid assemblages. In H. Wiltse (Ed.), Relating to things: Design, technology and the artificial (pp. 239-255). Bloomsbury.

Wrangham, R. W. (2009). Catching fire: How cooking made us human. Basic Books.

Publisher's Note Springer Nature remains neutral with regard to jurisdictional claims in published maps and institutional affiliations. 